\title{
Primary alveolar rhabdomyosarcoma: a horrendous presentation with miraculous remission
}

\author{
Anil Kumar Dhull
}

Department of Radiation Oncology, Post Graduate Institute of Medical Sciences, Rohtak, Haryana, India

\section{Correspondence to}

Dr Anil Kumar Dhull, anildhull@sify.com
To cite: Dhull AK. BMJ Case Reports Published online: 10 December 2012 doi:10.1136/bcr-2012007657

\section{DESCRIPTION}

Alveolar rhabdomyosarcoma constitutes approximately $1 \%$ of all paediatric tumours. Primary alveolar rhabdomyosarcoma of lip is a very rare pathological entity. ${ }^{1}$ Here is presented a case of primary alveolar rhabdomyosarcoma of upper lip treated with palliative external radiation therapy followed by combination chemotherapy.

A 5-year-old girl presented with painful swelling of upper lip of 3 months duration, which progressed rapidly. There was no history of other swelling. There was no history of any malignancy in the family. Local examination revealed an ulceroproliferative growth of $10 \times 8 \mathrm{~cm}$ size present over the upper lip involving bilateral nostrils and was locally advanced, causing difficulty in swallowing and respiration (figures 1 and 2). Histopathological examination confirmed the diagnosis of alveolar rhabdomyosarcoma.

The poor general condition of the patient as well as obstructive symptoms prompted us to treat the patient with palliative intention. The patient received palliative external radiation therapy and showed partial regression of the swelling after radiotherapy. The patient was further planned for intravenous combination chemotherapy with vincristine $1 \mathrm{mg}$, actinomycin $0.5 \mathrm{mg}$ and cyclophosphamide $400 \mathrm{mg} 3$ weekly for six cycles and after

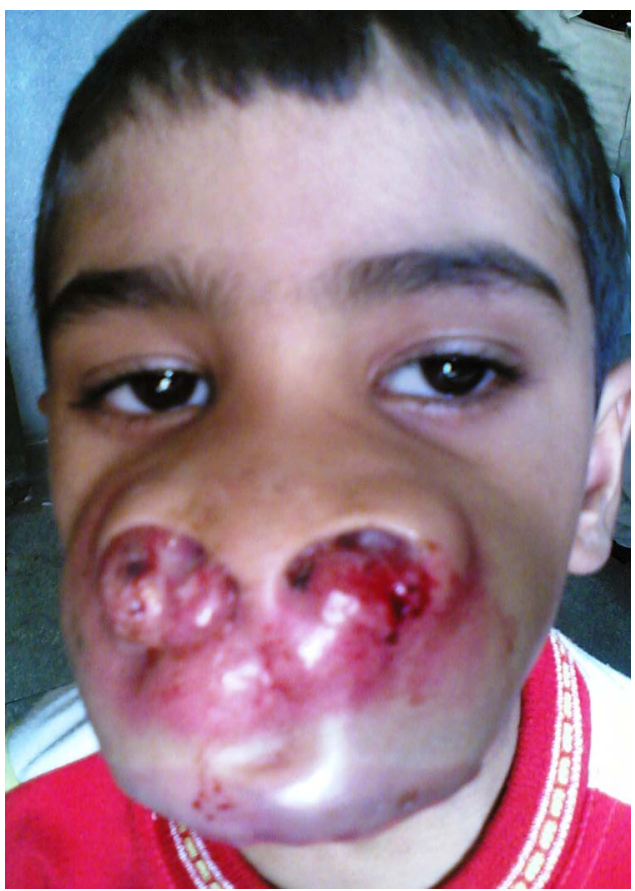

Figure 1 Anterior view showing a locally advanced growth over the upper lip involving bilateral nostrils.

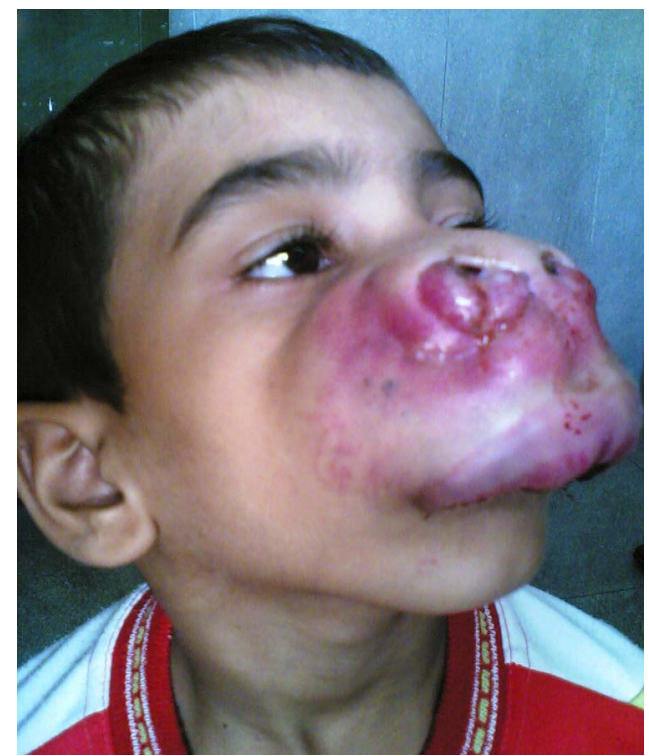

Figure 2 Lateral view of the growth.

6 months of the initial presentation, the patient was in complete remission as is evident from the serial photographs (figures 3-5). Malignancy at this rare site is uncommon and clinical management presents considerable challenges. ${ }^{1}$ Intensive multimodality approach should be tested, incorporating surgery, dose-intensive combination chemotherapy and radiation therapy. ${ }^{2}$ Future challenges include the

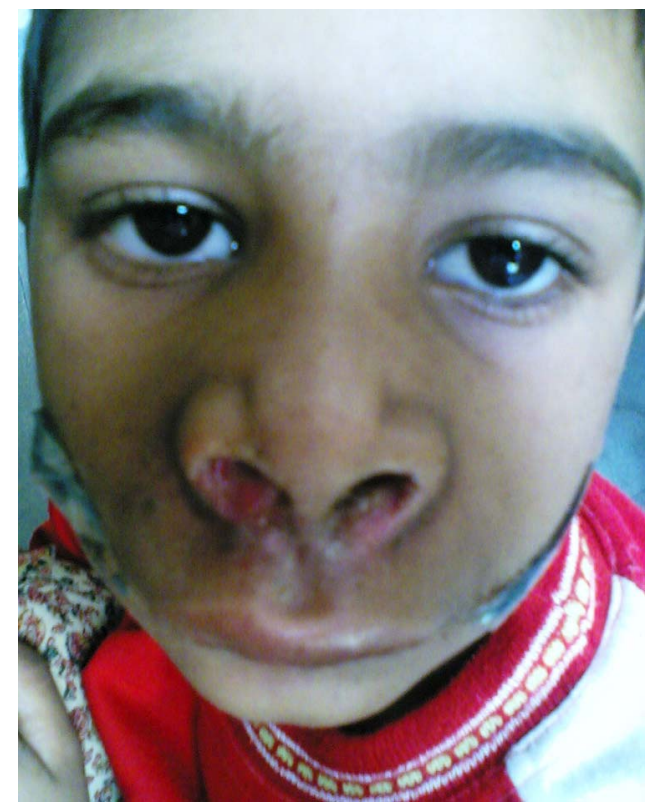

Figure 3 Clinical photograph at the end of palliative radiotherapy. 


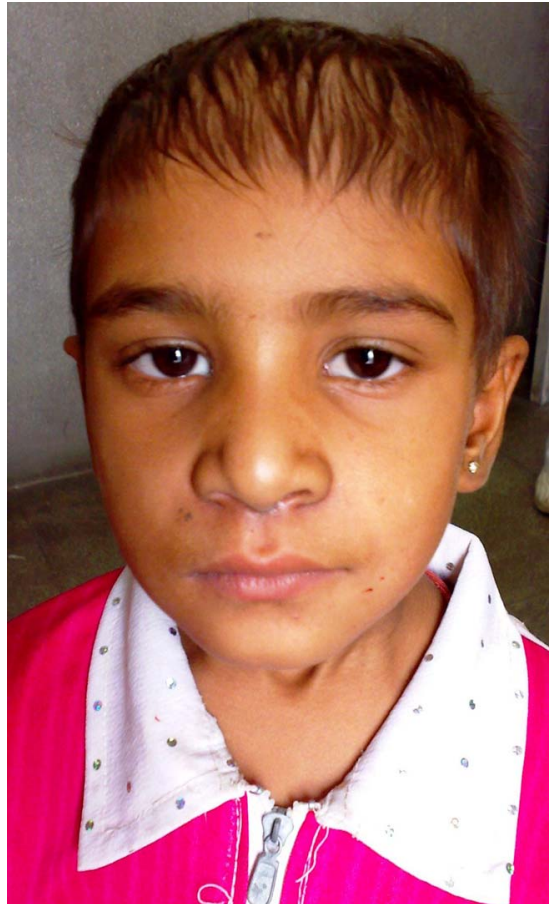

Figure 4 Post-treatment photograph after 2 months of completion of radiotherapy.

development of less toxic therapy for patient with localised disease and new approaches for patients with metastatic disease.

\section{Learning points}

- Primary alveolar rhabdomyosarcoma of the lip is a rare pathological entity and usually present in the aggressive form.

- External radiotherapy and adjuvant combination chemotherapy with vincristine, actinomycin and cyclophosphamide is very effective treatment protocol.

- Intensive multi-modality approach for treatment is recommended as the results are miraculous and complete remission of the disease is possible.

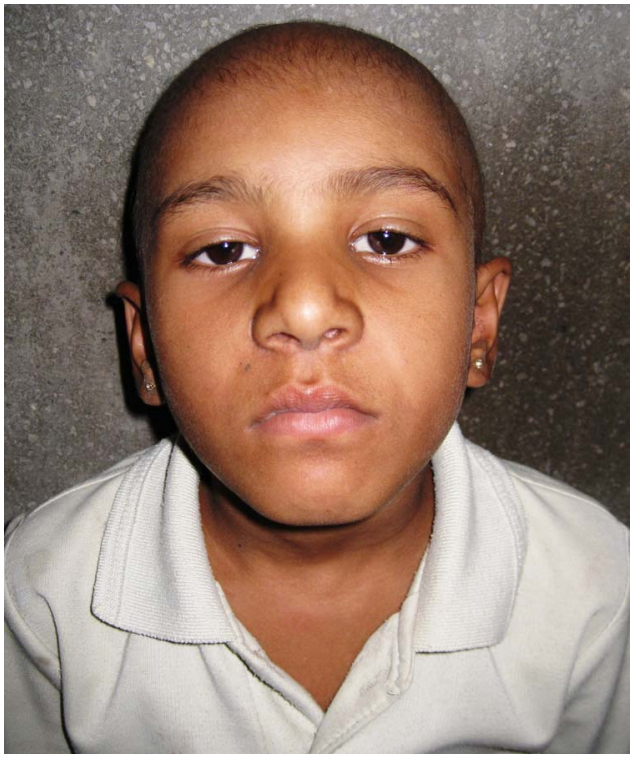

Figure 5 Post-treatment photograph showing complete remission after 6 months of completion of radiotherapy and six cycles of chemotherapy.

\section{Competing interests None.}

Patient consent Obtained.

\section{REFERENCES}

1 Company F, Pedram M, Rezaei N. Clinical characteristics and the prognosis of childhood rhabdomyosarcoma in 60 patients treated at a single institute. Acta Med Iran 2011:49:219-24.

2 Turner JH, Richmon JD. Head and neck rhabdomyosarcoma: a critical analysis of population-based incidence and survival data. Otolaryngol Head Neck Surg 2011;145:967-73.

Copyright 2012 BMJ Publishing Group. All rights reserved. For permission to reuse any of this content visit

http://group.bmj.com/group/rights-licensing/permissions.

BMJ Case Report Fellows may re-use this article for personal use and teaching without any further permission.

Become a Fellow of BMJ Case Reports today and you can:

- Submit as many cases as you like

- Enjoy fast sympathetic peer review and rapid publication of accepted articles

- Access all the published articles

- Re-use any of the published material for personal use and teaching without further permission

For information on Institutional Fellowships contact consortiasales@bmjgroup.com

Visit casereports.bmj.com for more articles like this and to become a Fellow 